\title{
Trust and Technologies of Sense. VR and Proprioception in Hamlet Encounters
}

\author{
Otília ÁRMEÁN \\ Sapientia Hungarian University of Transylvania \\ Cluj-Napoca, Romania \\ e-mail: armeano@ms.sapientia.ro
}

\begin{abstract}
This paper investigates the changing role of media devices in constructing fictive worlds through senses, and the changing relation we have to our senses. The demand for immersion in a virtual visual reality has its precedents, shown for example by the popularity of the kaleidoscope, the peeping box, the Guckkasten, or the panoramas. But while the immersive effect of these illusion spaces was based on visual perception, now we have multisensory interactive spaces that trigger our proprioception (body awareness and feeling of presence). The VR experience Hamlet Encounters offers a unique experience and exemplary use of distance, dislocation, and perception of one's own senses.
\end{abstract}

Keywords: trust, senses, VR, immersion, presence, technologies of sense

\section{Introduction}

Technology allows us to learn about ourselves extending our senses, testing our perception, anchoring us in different environments. In parallel to representing the natural and cultural space that surrounds us, it is more and more about constructing imaginative spaces that reveal something otherwise hidden to our senses. Seeing is believing, so states the saying, meaning that truth will be recognized once perceived. But can we trust our ability to believe what we see after so many deceptions? Media can extend the human body and its senses, but in the meantime human perception also adapts to be extended. What we are is interdependent of the media we use. But our sense of what we are can be triggered differently by distinct media environments. This paper investigates the role of a VR environment in the participants' proprioception. 


\section{Media Archaeological Incursion}

The idea that humans have not changed so much during the history of civilization and that every new development is connected to something already known before appears as an underlying principle in the book The Language of New Media by Lev Manovich: "By looking at the history of visual culture and media, in particular cinema, we can find many strategies and techniques relevant to new media design" (Manovich, 2001: 314). Bolter and Grusin's theory of remediation or Marshall McLuhan's theory of technological determinism also serve arguments for the thesis that cultural history serves as a unique source for developing a novel theory of new media or for understanding the development of the media landscape. It may simply occur that new is not so new and that there are some basic interests, drives that explain our enthusiasm for new media tools, for example VR settings. Oliver Grau argues in his book about the history of image spaces of illusion that virtual reality has always been part of the relationship of humans to images (Grau, 2003: 5). Furthermore, he describes this relationship as a recurring cycle:

When a new medium of illusion is introduced, it opens a gap between the power of the image's effect and conscious/reflected distancing in the observer. This gap narrows again with increasing exposure and there is a reversion to conscious appraisal. Habituation chips away at the illusion, and soon it no longer has the power to captivate. It becomes stale, and the audience are hardened to its attempts at illusion. At this stage, the observers are receptive to content and artistic media competence, until finally a new medium with even greater appeal to the senses and greater suggestive power comes along and casts a spell of illusion over the audience again. This process, where media of illusion and the ability to distance oneself from them compete, has been played out time and again in the history of European art since the end of the Middle Ages. (Grau, 2003: 152)

Looking at pictures has always been a favourite occupation of humans, and the power of images seems to be just as strong as in the beginnings. Susan Sontag's essay On Photography starts with the sentence: "Humankind lingers unregenerately in Plato's cave, still revelling, as its age-old habit, in mere images of the truth" (Sontag, 1973: 1). What we have are "mere images of the truth", but they teach us how to revel, how to be human, how to live in alignment with the lingering humankind. Even Grau takes this image and transforms it in a fable we can learn from: "Obviously, like Plato's prisoners in the cave, what we need to do is to turn toward the light, to face the new and, armed with our knowledge, confront it squarely. The question is not to find a way out of the cave, for there is no way out of the history of media" (Grau, 2003: 346). 
Grau's question is whether the newest media tools with all their arsenal of illusion and immersion-creating effects leave room for critical distancing and reflection. I will highlight two devices that aim for immersion, but even so they facilitate distancing and teach media competence: the peep egg and the camera lucida.

In the history of media, there was a popular viewing device in the Victorian era, called the peep egg. This device allows one person to view two still images through a monocular lens. "The peep egg is made of alabaster, so that light passes through the body of the device and no other source of illumination is required. The body is fitted with twin alabaster handles rotating a spindle so that two or three prints can be mounted inside the body of the egg. Each person turns the handle at his/her own speed to see each of the images" (Mellby, 2008). The device was based on a loop, e.g. "sequence of images featuring complete actions that can be played repeatedly" (Manovich, 2001: 297). The loop brings repetition, distance, and a focus on the medium, while the mix of realities brings in-betweenness and marks the position of the outsider/observer, who is distanced from the world s/he is observing. Magdolna Kolta reminds us that these optical images and others seen in marketplaces conveyed unknown cities, unknown landscapes, and celebrated events for the viewers at that time, and, last but not least, they brought exotic and new information in one's life that could be a topic to talk about in companies, at restaurant tables, and in salons for a long time (Kolta, 2003). The viewers also learned something about visual literacy. They learned that a picture is a two-dimensional representation of the three-dimensional physical reality. It is an abstraction but also a possibility to experience something virtually that is unavailable for direct, immediate, physical contact. We have in this experience two different realities brought together in a mixed reality space. The distance between the two layers is always interesting, the immersion felt thanks to the device (detaching from the natural environment) and the presence of something physically absent.

The second device is called the camera lucida. It is an optical device that permits drawing with the help of a projection: a prism makes it possible to simultaneously see the real thing and the projection of that on the paper. The drawer has only the task to follow the projection, so the drawing will be accurate and fast. In his essay about photography, Roland Barthes concludes that: "It is a mistake to associate Photography, by reason of its technical origins, with the notion of a dark passage (camera obscura). It is camera lucida that we should say (such was the name of that apparatus, anterior to Photography, which permitted drawing an object through a prism, one eye on the model, the other on the paper)" (Barthes, 1980: 106). This optical device, this apparatus, serves as a metaphor for what photography represents, its state of an absence made present. Camera lucida joins two different realities together as two layers or strata.

It is important here to emphasize the fact that all the preceding optical devices were for making a two-dimensional representation familiar to the audience. They 
taught abstraction to the viewer and also slowly showed that a representation is similar but not equal to the represented reality.

Nowadays, "new forms of sense and sensations are increasingly being produced and measured by [contemporary] technologies" (Salter, 2017: 175). VR devices and experiences try to make the two-dimensional representations threedimensional and teach us how to act and interact in these computed, amplified, augmented, mediated, virtualized spaces. The difference between previous immersive devices and VR seems to be a quantitative one, having now a much more complex and synchronized sensorium integrated in the experience. But a more attentive perspective reveals that VR productions also operate with the joining of two realities, the juxtaposition of two experiences that brings as a result distance, dislocation, and, paradoxically, trust.

\section{Media of Attraction and Technologies of Sense}

Grau (2003: 152) argues that the strongest moment of illusion for every new immersive media is the moment of appearance. The effect of illusion will decrease in time with domestication, habituation, and media competence, but when it arises "the medium becomes invisible" (Grau, 2003: 340). In contrast, Rebecca Rouse introduces the meta-category of "media of attraction" and speaks about four characteristics as common threads across media of attraction: 1. unassimilated, 2. interdisciplinary, 3. seamed, 4. participatory. Seamed is an interesting concept in this group, and it means that media of attraction is not self-sufficient, it exposes the specificity of the media itself: "the audience to media of attraction is made explicitly aware of the technology itself. If leveraged well, this awareness can operate to allow audiences to take meta-pleasure in the mediation presented, in addition to the feeling of immersion” (Rouse, 2016: 101). Ágnes Karolina Bakk defines in her paper many important and recurrent notions related to VR productions (for example, the differences between 360-degree videos and VR, immersion, presence, interactivity, atmosphere, performativity) and concludes that immersion is enhanced through the seamed traits: "the seamed character of VR experience is actually enhancing its immersive effect. Immersion becomes a dynamic function that, through the interactive characteristics of the art form, always presents to the viewer a new layer of experience" (Bakk, 2019: 154). In this sense, the seamed quality can be a lasting criterion, not only a characteristic in the media of attraction phase in the history of VR.

VR productions are often described as being hybrid media, using many different media elements. They offer multisensory experiences by creating multisensory environments that regularly challenge our senses (using not only visual and auditory impressions but sometimes stimulating our haptic and gustatory senses 
too). In an ideal immersion, these different sensorial layers would work together, creating a total illusion. But most of the creators of these VR productions are artists who want to look behind the curtains of illusion and research the mediation (what is a media and what it does to us), the self (how the subjects are created through different experiences), the technologies of the self. VR productions can be regarded as created for such investigations, and through interaction they provide a safe place for the private experiences of the users. Namely, the users interact with the created environment in their own rhythm, according to their own inquisitiveness, and perceive only what is meaningful for them. Salter accentuates that "when you deal with questions of sensory perception, how environments or the external world meet the human perceptual system, you can't be passive. You are a performer in the sense that philosophers like Alva Noë have argued - you perform your perception of the world in an active way" (Salter, 2015).

Performing the perception means that we become aware of processes of our body that usually work in the background. Proprioception is exactly body awareness and feeling of the presence. In a mediated environment, like a VR production, we not only use our bodies in a more conscious way, but we become aware of the fact that - as Caroline Jones puts it - "the human sensorium has always been mediated. But over the past few decades that condition has greatly intensified. Amplified, shielded, channelled, prosthetized, simulated, stimulated, irritated - our sensorium is more mediated than ever before" (Jones, 2006: 5). The mediation of the human sensorium happens through techniques like the "truth games", defined by Michel Foucault when he speaks about the technologies of the self. According to him, there are four major types of these "technologies" that we use in order to understand ourselves and the conditions of our existence: (1) technologies of production which permit us to manipulate things; (2) technologies of sign systems which enable us to use signs and symbols in order to construct meanings; (3) technologies of power which transform us in compliant subjects; (4) technologies of the self which are performed by the individuals themselves on their own bodies and souls towards a kind of self-transformation "in order to attain a certain state of happiness, purity, wisdom, perfection, or immortality [...] Each implies certain modes of training and modification of individuals, not only in the obvious sense of acquiring certain skills but also in the sense of acquiring certain attitudes" (Foucault, 1988: 18).

Salter introduces a fifth category, the technologies of the senses, "defined as those techniques, devices, procedures or strategies that aim to produce bodies and selves with other kinds of perceptions - perceptions that extend routine ways of seeing, hearing, feeling, touching and tasting the world" (Salter, 2017: 175). The immersive media takes advantage of our perception routines but also has the advantage to position the experiencer in a new space, in a different kind of sensorium than we are used to. 


\section{VR and Proprioception in Hamlet Encounters}

The example presented in this article for examining all of the above is the VR production Hamlet Encounters (2018, Crew Group Netherland, attended at the international conference Intermediality Now: Remapping In-Betweenness, 18-20 Oct. 2018, organized by Sapientia Hungarian University of Transylvania, Cluj-Napoca). ${ }^{1}$ It enables the participant to live an experience with a mix of $3 \mathrm{D}$, virtual reality, and theatrical elements. ${ }^{2}$ The production itself is a research project gathering specialists from different fields (artists, scholars, technicians) investigating the role of new immersive technologies resulting in new modes of creating, presenting, and experiencing possible worlds.

This production is a one-by-one experience which begins already in the waiting area. The participants get accommodated with the fictive world thanks to a screen which projects the view from the headset of the experiencer who is just exploring the virtual reality world. The waiting participant sees the real, empty, and marked space, and the experiencer in it sees the director sitting at an outside table providing instructions to the facilitators of the VR team. Simultaneously, $\mathrm{s} / \mathrm{he}$ is able to check what the experiencer is seeing in the virtual image space. This outside experience helps to build trust both in the environment and the staff of the VR production. The technical parameters achieve that "not only the illusion is visible, but the creation of the illusion as well" (Kattenbelt, 2019).

The participant is mostly a visitor until the point where s/he gets the VR headset and literally steps into the VR world. The outside experience is being put under observation now that the visitor becomes performer in the fictive world, even if the price of this border crossing is the loss of the image of the physical body and the acquiring of a ghostlike state. The differences between the inside and outside experiences are highlighted by Robin Nelson (Nelson, Joris, Kattenbelt, 2018), who also specifies that "the play between them is what ultimately re-functions perception”. It re-functions proprioception as well.

1 Credits (http://www.crewonline.org/art/projects; accessed on: 24.08.2020): Concept: CREW; Directors: Eric Joris \& Mesut Arslan (Platform 0090); Actor: Rashif El Kaoui (KVS); Dramaturgy: Geraldo Salinas (KVS), Robin Nelson (ex-Central School of Speech \& Drama, University of London), Aneta Mancewicz (Univ. Birmingham) \& Chiel Kattenbelt (University of Utrecht); Intern dramaturgy: Sofie Revet; Creation VR production "Hands-On Hamlet": CREW \& Urland; Intern dramaturgy "Hands-On Hamlet": Jesse Van der Heijden; Director VR production "HandsOn Hamlet": Marijn Alexander de Jong \& Eric Joris; Actors VR production "Hands-On Hamlet": Nadia Babke, Thomas Dudkiewicz, Robin Nelson, Paulette Smit, Jesse Van Der Heijden, Bram Van Der Kelen \& Koen Van Kaam; Technological coordination: Koen Goossens; 3D design: Joachim Bouvie, Emmanuel Tomozei \& Eric Joris; Production Hamlet Encounters: CREW \& Platform 0090 \& KVS; special thanks to Joris Weijdom (HKU) and Kasteel Van Gaasbeek (BE).

2 Some technical data about the staging of the production in Cluj-Napoca: * large premises in the basement of the university building with a conference room and a separate area for the VR setting; * single visitors who attend the experience one by one; * 10 -minute introduction time, 
The image space the visitor is entering is a castle with various rooms where the experiencer can go into. There are figures playing different characters from Shakespeare's Hamlet, engaged very lively in their conversations. The experiencer can stop and listen to the dialogues or simply go through them like a ghost. There are also some uncanny bubbles I can put my head into. The bubbles are like worlds in the experienced world revealing how the different scenes were put on stage: actors, wires, cameras, all kinds of devices. In the bubble, I am an observer placed above the stage. I must admit to myself that I am much more interested in the created space than in the narrative of the virtual world. At a certain point, there are stairs. I know that the actual space I am experiencing is a flat floor, but I cannot help having a vertigo feeling. My equilibrioception (perception of balance) is triggered. I try to find the handrail while I am bending my knees to go down the stairs (doing by that exactly what the previous visitor did and I said to myself that I would not). I have to negotiate the space because what I know from the outside experience and what I see in the VR stage do not correspond. Then I am invited to sit down on a chair in the virtual reality, and I know that a technician will bring now an actual chair I can actually sit on, and I sit down. I am aware that the guiding voice in my headset does not belong to the image world though it is part of the experienced production. I am also aware that a technician is behind me holding the cord (which functions like a safety rope between the two worlds).

During the immersion in this VR world, I have an intense desire to explore untrodden paths, to find places undiscovered by others. Being a single visitor, I feel like I am in the centre of the experience, like I am the protagonist, everybody just watching me and making all the necessary adjustments for me to have a perfect journey. The voice asks me what I see, how I feel, what triggers me. My experience is important not only for me but for the others too.

After the experience, I am asked if I saw something unusual. I have the possibility to write my impressions down. It would be nice to read the written experiences of the other visitors.

Although I know that what I see is not real, I must accept that I am acting according to what I see. I have to negotiate with my bodily actions how to move in a place that shows itself like something it is not. How to go down a staircase where there is no staircase? It is a very uncommon feeling, tormenting even after the experience in question. Why were my eyes so convinced about the stairs? Why did I believe my eyes if I knew that the actual space was a flat floor? Why is this experience reinforcing the trust in my visual capacities if I now have such a solid proof that not everything I see is necessarily true?

Even if what I see is constructed, it has the convincing force given by the senses. As a picture the staircase would not be interesting, but as a space that

observation of the previous visitor's journey, 10-minute experience + after-journey time, writing feedback to the team; * 1 director, 1 coordinating technician, 1-2 technicians. 
I have to experience it becomes a true environment. As I have to move in this environment, it is safer to act in concordance with what I see and then with what I know. The sight of a staircase in an immersive environment - in the inside of the image, it brings the need to act towards it as it is seen, not as it is known. My sensorial experience is taking over, and I am in the position of experiencing how my sensorial agency works. The negotiation of the space is a complex process, and it has more likely a positive outcome if I trust my eyes. Even if what I see is constructed, it has the convincing force, and in this VR project I am experiencing exactly that convincing force of my visual perception.

The experience is much more about this - actively perform my own perception - than following the drama of Hamlet. The choice of Hamlet as the theatrical frame is important because Shakespeare's play deals with a historical time and a narrative moment when everything becomes questioned, the whole world is out of joint, conflicted. In the frame of the VR project, the participant finds him-/ herself experiencing the characteristics of Hamlet's time. The makers of the virtual reality theatre To Be with Hamlet (NYU Tandon School of Engineering) highlight as a learnt lesson that a VR production "can be used to shed new light on canonical theatrical texts by giving the audience a more visceral experience of the world of the play" (Gochfeld-Molina, 2017: 47). Hamlet is put on stage with this effect: adjacent enough to understand what is happening but intriguing enough to keep the participant alert.

Thinking about the future of narrative in cyberspace, Janet H. Murray (2017) includes the example of Hamlet even in the book's title: Hamlet on the Holodesk. Murray argues that exactly like "Shakespeare's extensive use of soliloquy in Hamlet is an appropriate technical innovation to capture [...] the Renaissance fascination with thinking itself and with separateness of the individual life", cyberdrama will create "simulated environments that capture behavioural patterns and patterns of interrelationships with a new clarity. [...] The new medium can take us even further in both directions, looking deeper into the human mind and encompassing even more of the external social world" (Murrey, 2017: 259-260).

\section{Should We Question or Trust Our Senses?}

Virtual reality has a powerful potential to familiarize us with other realities and different points of view, to increase our empathy towards foreign people, foreign problems, and foreign life situations that are not accessible to us physically. But VR also brings a sense of danger or uncanniness that our knowledge and beliefs are not true anymore, or they are not helping us anymore. Our self, our body becomes foreign before our very eyes and controlled by the proprieties of the device or headset we use. 
VR technology has so far been mainly considered as a kind of new form of film which goes one step further: you are no longer a disappearing invisible witness like in mainstream film, who is allowed to be everywhere in the world in order to understand what the film is about, but you are actually in the centre of it. Of course, you pay the price for it because the first thing you notice in the virtual space is that your body has disappeared. "Where am I?" "Where is my body?" You immediately sense how your eyes and ears are redefined, and then you have to find out with your physical body how to relate to it. (Kattenbelt, 2019)

Anna Eifert argues that in this new world of telematics and telepresence we are experiencing a loss of confidence in our perception system. Our senses cannot be trusted anymore, and this process began with the medium of the photography. Photography should have been a realistic medium that was supposed to show us the world as seen around us. However, photos did not show the reality seen, but they showed that reality differs from what we see. The conclusion is that our eyes are not to be trusted (Eifert, 1997: 395). The torrent of images that are received by our eyes as augmented and extended every day and from everywhere are not helping in the discernment between what is important to be seen and what can be dismissed. Our vision is overwhelmed, and lately the mistrust drifts towards the other senses too. Eifert concludes that we need a new balance, a new synchronization between our active and passive senses so that "we get the picture", meaning that our perception of reality recovers. Meanwhile, being in the picture, in immersive environments could actually help with increasing awareness towards perception and senses, with rewiring the system of the senses.

Derrick de Kerckhove writes in his essay Touch versus Vision: Äesthetik Neuer Technologien about the trust we feel towards our senses and why that is so important:

The only sense in which we can truly trust is touch, because it is through touch that we really exist [denn er ist da, wo auch wir wirklich sind]. Through the vehicle of electricity, we are in contact with the whole world. Thus only the rediscovery of proprioception will make it possible for us to trust in our feelings, in the sense not of emotions which accompany us in daily life, but of the much deeper sensation of being in the centre of our own perception of the world that surrounds us. This form of intercourse with information . . . is rooted in a fully realized proprioceptive sense. It calls on us to transform our personal centre of reference [Bezugszentrum] into a "point of being". (cited in Hansen, 2004: 217) 


\section{Conclusions}

The greatest impact of the VR experience on proprioception consisted in recognizing the impossibility to act against the sensorial knowledge. Firstly, this insight brings paradoxically trust in the senses because they are powerful enough to be treated seriously. Secondly, it brings distance and the spaces required for recognizing proprioception and learning about it. In a space of highlighted perception, we gain perspective on the technologies we use, on the mediation of our sensorium.

The question regarding the trust in our ability to believe what we see can be answered as it follows: what we see presents itself so powerful to the cognition system that we can only adapt to fit to the reality seen. Experiencing the VR environment reinforces trust in the senses because it helps us recognize ourselves and what we truly are.

It is more and more important to be aware of processes that we have taken too long for granted since there is an imminent danger to loose these types of technologies: "The self-propagating, self-escalating increase in non-perceptual sensible data generated by twenty-first-century media profoundly affects the economy of experience, such that our (human) experience becomes increasingly conditioned and impacted by processes that we have no direct experience of, no direct mode of access to, and no potential awareness of" (Hansen, 2015: 8). VR projects, immersive experiences may offer exactly the tools needed for balancing non-perceptual with perceptual, indirect with direct, unawareness with awareness, inertia with agency.

Media history helps us to draw the big picture, to approach the technologies of perception and shows the ways how skills and attitudes are acquired. Our training has many methods, stops, and vigorous digging-in phases, but it is continuous, and there is no way out of it.

\section{References}

Bakk, Ágnes Karolina. (2019). Sending Shivers down the Spine. VR Productions as Seamed Media. Acta Universitatis Sapientiae, Film and Media Studies 17: 143-156. DOI: 10.2478/ausfm-2019-0020. http://www.acta.sapientia.ro/actafilm/C17/film17-09.pdf (accessed on: 24.08.2020).

Barthes, Roland. (1980). Camera Lucida. Reflections on Photography. Translated by Richard Howard. New York: Hill and Wang.

Eifert, Anna. (1997). A kép az eltûnés esztétikájában. Interaktív environment mint kinesztetikus tapasztalati tér [The Image in the Aesthetics of Disappearance. Interactive Environment as a Kinesthetic Space of Experience]. In: Bacsó, Béla 
(ed.), Kép - Fenomén - Valóság [Image - Phenomenon - Reality]. Budapest: Kijárat, 381-396.

Foucault, Michel. (1988). Technologies of the Self. In: Martin, Luther H.-Gutman, Huck-Hutton, Patrick H. (eds.), Technologies of the Self. A Seminar with Michel Foucault. Tavistock Publications. The University of Massachusetts Press, 16-49.

Gochfeld, David - Molina, Javier. (2017). To Be with Hamlet. In: Weijdom, Joris (ed.), Mixed Reality and the Theatre of the Future. Fresh Perspectives on Arts and New Technologies. Brussels: IETM - International Network for Contemporary Performing Arts, 47-54. https:/www.ietm.org/en/system/files/publications/ ietm_fp_mixed-reality_march2017_1.pdf (accessed on: 24.08.2020).

Grau, Oliver. (2003). Virtual Art. From Illusion to Immersion. Transl. by Gloria Custance. Cambridge, Massachusetts - London, England: The MIT Press.

Hansen, Mark. (2004). New Philosophy for New Media. Massachusetts Institute of Technology

(2015). Feed / Forward. The Future of $21^{\text {st }}$ Century Media. Chicago.

Kattenbelt, Chiel M. (2019). Performativity and Worldmaking. Interview with Chiel M. Kattenbelt by Ágnes Karolina Bakk. Acta Universitatis Sapientiae, Film and Media Studies 17: 169-178. DOI: 10.2478/ausfm-2019-0022. http:// www.acta.sapientia.ro/acta-film/C17/film17-11.pdf (accessed on: 24.08.2020). Kolta, Magdolna. (2003). Képmutogatók. A fotográfiai látás kultúrtörténete [Image Displayers. The Cultural History of Photographic Vision]. Magyar Fotográfiai Múzeum [Hungarian Museum of Photography]. http://www.fotoklikk.hu/fm/ kepmutogatok/iii_b.html (accessed on: 24.08.2020).

Manovich, Lev. (2001). The Language of New Media. Cambridge: The MIT Press. Mellby, Julie L. (2008). A Peep Egg. https://www.princeton. edu/ graphicarts/2008/05/a_peep_egg.html (accessed on: 24.08.2020).

Murray, Janet H. (2017). Hamlet on the Holodeck, Updated Edition. The Future of Narrative in Cyberspace. The MIT Press.

Nelson, Robin-Joris, Eric-Kattenbelt, Chiel. (2018). Theatre In-Between Live Action, VR and Cinema: Crew's Hamlet Encounters. The presentations of Robin Nelson (University of London), Eric Joris (Brussels, founder of Crew), Chiel Kattenbelt (Utrecht University) at the international conference Intermediality Now: Remapping In-Betweenness, 18-20 Oct. 2018, organized by Sapientia Hungarian University of Transylvania, Cluj-Napoca. https://www.youtube. com/watch?v=yGWsCp26Cco (accessed on: 24.08.2020).

Rouse, Rebecca. (2016). Media of Attraction: A Media Archaeology Approach to Panoramas, Kinematography, Mixed Reality and Beyond. In: Nack, F.-Gordon, A. S. (eds.), ICIDS 2016. LNCS, vol. 10045. Cham: Springer, 97-107.

Salter, Chris. (2015). Displace 2.0: Mediation of Sensations. A Conversation with Chris Salter. Digicult. https://digicult.it/news/a-conversation-with-chris- 
salter-on-displace-2-0/ (accessed on: 24.08.2020). (2017). Technologies of Sense. Expanding the Sensorium in the Age(s) of Immersion. In: Limits of Knowing. Catalogue. Berlin: Kerber Verlag, 174-183. (2019). Presence Is the Lingua Franca. ZipScene Magazine. Performing arts\&games\&tech\&more. https://zip-scene.com/2019/06/10/presence-is-thelingua-franca/ (accessed on: 24.08.2020).

Sontag, Susan. (1973). On Photography. New York: Rosetta Books LLC.

\section{Cite as:}

Ármeán, O. (2020). Trust and Technologies of Sense. VR and Proprioception in Hamlet Encounters. Acta Universitatis Sapientiae, Communicatio 7: 1-12. DOI: 10.2478/auscom-2020-0001. 